\title{
The Nature of Snow*
}

\section{By Gerald Seligman}

$\mathrm{A}^{\mathrm{L}}$ LL ice and snow forms are crystalline. To demonstrate the crystalline structure of even an apparently non-crystalline body such as a shapeless block of ice, Tyndall passed a beam

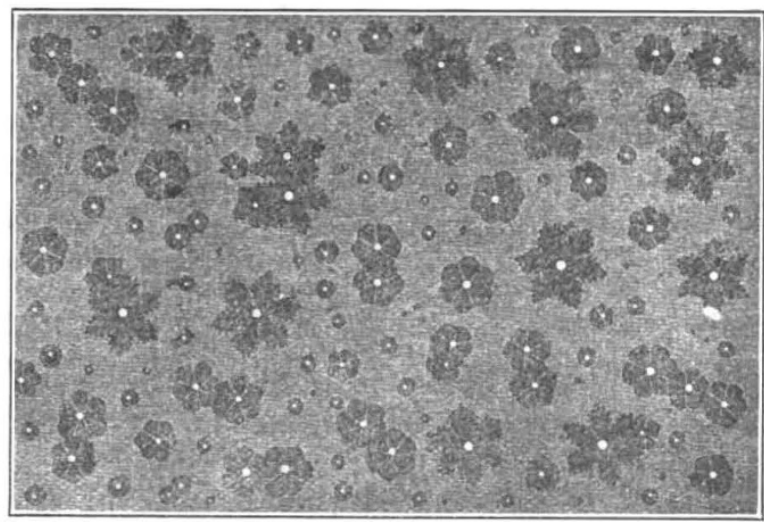

Fig. 1.

NEGATIVE FIGURES IN ICE.

Reproduced from "The Glaciers of the Alps", by J. Tyndall (by courtesy of Sir John Murray).

of light through it. If we repeat this experiment we find that hexagonal cavities are produced and that the process of crystallization is, as it were, reversed, so that we get what are sometimes called 'negative crystals', or as I prefer to call them, 'negative figures', within the body of the ice (Fig. 1). As the action of the beam proceeds, each figure becomes filled with the water which occupied it as ice. In the centre of each figure a bubble forms, which, in reality, is a vacuous sphere due to the water taking up less space than the ice.

These 'negative figures' are very useful in telling us the arrangement of the crystals in a mass of them, such as, for example, in glacier ice. They lie at right angles to the principal axes of the ice crystals, and parallel to the original freezing surface. Therefore, in pond ice, as we should expect, the 'negative figures' are found parallel to the surface of the pond, and this confirms that the ice crystals grow with their principal axes perpendicular to the surface. In artificial ice they are often found more irregularly placed, the incidence of the refrigeration having been irregular.

* From the Friday evening discourse at the Royal Institution delivered on January 22.
In glacier ice we find that the crystals are orientated without any order, for the reason that the glacier crystals have grown from snow grains, each crystal preserving the haphazard orientation of the original snowflake as it fell on to the surface.

\section{Sublimation}

Everyone who wishes to understand snow must understand sublimation. Sublimation is, of course, the transition of a solid into a gas and its immediate reconversion into the solid, without entering the liquid phase. Many substances do this, and ice is one. Under suitable conditions it evaporates direct into water vapour, and, again under suitable conditions, this will reconsolidate, or, in loose parlance, sublime, into ice without any water appearing.

The evaporation of ice into water vapour has probably been seen by every winter visitor to the Alps ; on a dry, warm day a patch of snow on a rock will vanish into thin air without leaving a trace of moisture. Among other factors, principally those of wind and the relative humidity of the air,

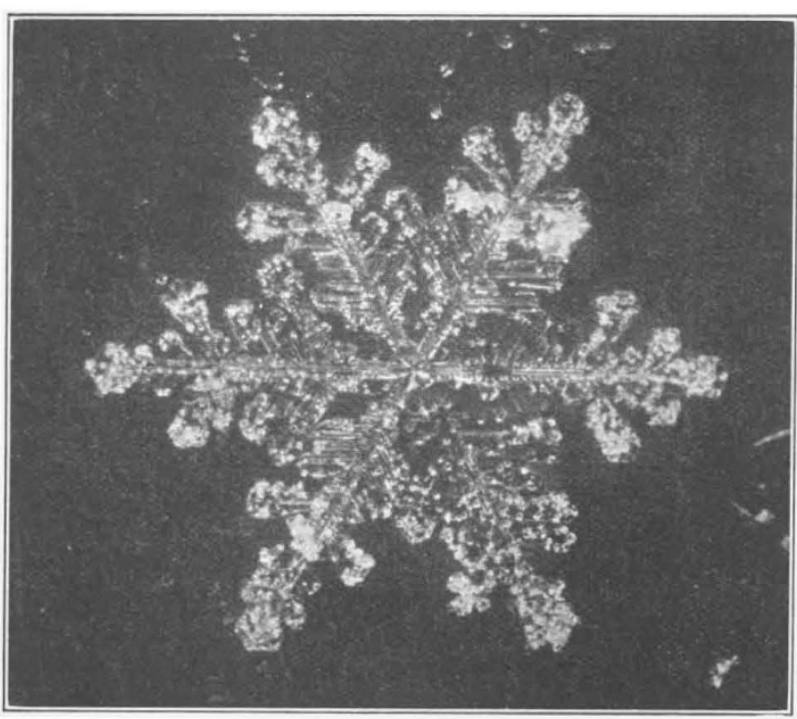

Fig. 2 .

A TYPICAL DENDRITIC SNOWFLAKE $(\times 15)$. Photogra ph by G. Seligman.

ice evaporation is promoted by a relatively high ice temperature; the reconsolidation of this vapour into ice is brought about by a relatively 
low temperature. There is scarcely a single snow phenomenon that does not to some extent depend on sublimation. The genesis of snow itself-the growth of the snowflake-is nothing but the sublimation of water vapour out of a supersaturated atmosphere. In this case sublimation starts upon nuclei floating in the air, which may consist of grains of dust, pollen or chemical salts.

\section{SNOWFLAKES}

The designs of snowflakes are probably infinite. Bentley, a distinguished American experimenter, photographed some 5,000 types, and believed that he had only attacked the surface of the possibilities.

The simplest form of snowflake is a hexagonal plate about ten times greater in diameter than in thickness. Its diameter might be as large as $1 \mathrm{~mm}$. or $2 \mathrm{~mm}$., or much smaller. More common in the Alps are the dendritic flakes (Fig. 2). When snow falls at a temperature close to freezing point, we get the large cotton-woolly aggregates which are so common in Great Britain, the word 'flake', in fact, denoting its woolly character.

Another form of flake is the prism, and its variant, the needle. Fascicular bundles of needles frequently cross each other at $90^{\circ}$, departing from the usual $60^{\circ}$ symmetry of the ice crystal. This is extremely rare in other forms of ice crystal, except in the case of window hoar-the beautiful crystals which form on the inside of windowpanes-and in this case also it is of constant occurrence.

The growth of dendritic flakes was explained by Wegener from work done on the crystallization of iodoform by Lehmann in 1888. Using a slightly

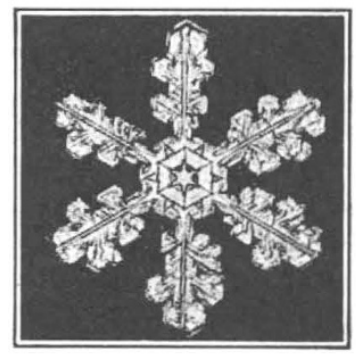

Fig. 3 .

supersaturated solution, Lehmann stated that first of all a tiny hexagonal crystal formed, and that immediately surrounding it the solution was only saturated, the supersaturated area remaining a little distance away. Consequently, the corners of the hexagon, being closer to the supersaturated part, would grow out, until liquid could penetrate between the rays so formed and build side growths upon them.
Working with iodoform, we have not so far been able to find these two degrees of saturation in the laboratory, but it is a fact that in the sublimed ice crystals which grow on windows, the growing crystal does clear a space all round it. This certainly lends colour to what Wegener has deduced from Lehmann's work. I have observed this space again and again, moving outward as the crystal grows at the expense of the tiny frozen moisture drops covering the pane.

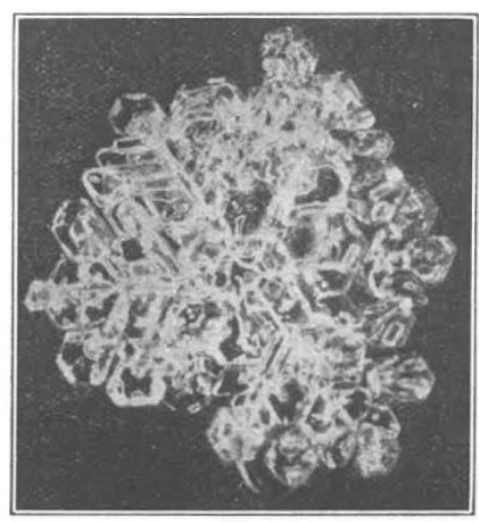

Fig. 4.

A SNOWFlake 'ICED-UP' TO FORM A FLAT PLATE OF ICE $(\times 10)$.

Photograph by G. Seligman.

Wegener showed, too, that the greater the difference between the vapour pressure of the ice of a flake and that of the surrounding atmosphere - the vapour pressure gradient-the more it favoured the growth of dendritic rays. The lower the vapour pressure gradient, the more the growth of solid plates was encouraged.

With this information it is not very difficult to trace the life-history of a snowflake. Taking the one shown in Fig. 3: at high altitudes, where the vapour pressure gradient was low (owing in this case to temperature and temperature differences being low) the central hexagonal plate was formed. The cold flake then fell to a warmer region, where the vapour pressure gradient increased, and the six rays shot out. Then perhaps it fell out of its snow cloud, when, for another reason (in this case that of lower saturation) the vapour pressure gradient decreased again; a more solid growth resulted and it assumed its final form.

In a converse manner we may be able to obtain a message of the meteorological conditions high up, from the structure of flakes as they reach the earth. This has already been done to some extent, but Nakaya's recent work in making flakes under con. trolled conditions should enable this, perhaps, valuable addition to meteorological knowledge, to make great strides. 


\section{FiRnification}

In any alpine winter snowscape it seems as though Nature has stood still under its winter mantle, and that all is peace. Yet, in truth, the snow cover is a vast and active laboratory in which the flakes are made to undergo incessant and increasing change, until the time when they disappear in spring and commence their long journey to the sea, or, at high altitudes, become converted into glacier ice.

These changes are called 'firnification'. When snow falls, it lies on the ground in the loosest and most impalpable condition. Its specific gravity at this time is about 0.06 , that is to say, $1 / 15$ ice, $14 / 15$ air, but under certain conditions of calm and

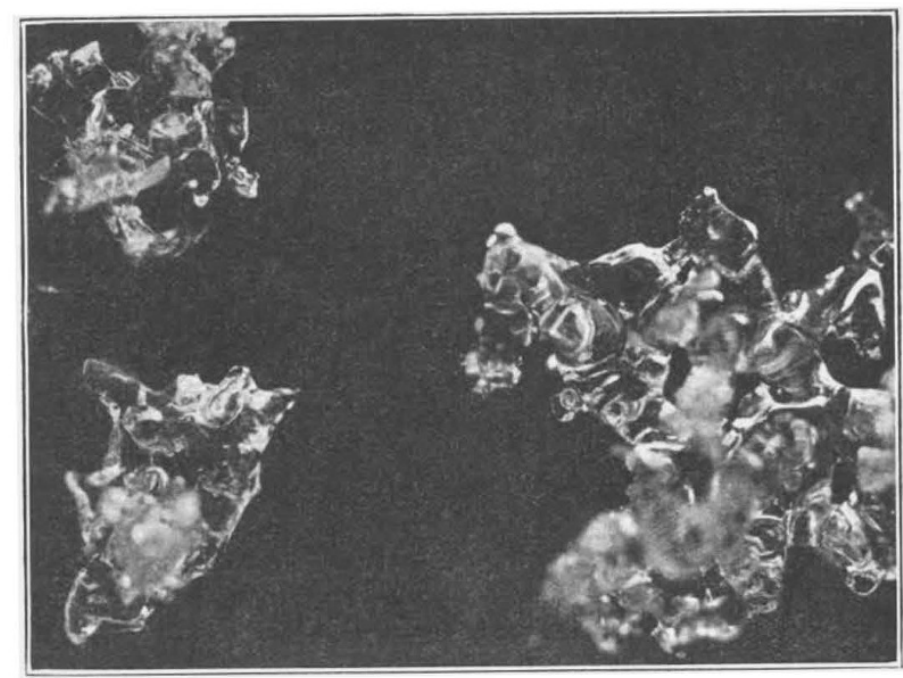

Fig. 5 .

ADVANCED FIRN SNOW; SHOWING THE CEMENT BINDING THE GRAINS TOGETHER $(\times 7)$.

Photograph by G. Seligman.

low temperatures, it may be only 0.01 , that is 1/92 ice, $91 / 92$ air!

The snow immediately begins to settle. The sharp points of the rays evaporate, and the flakes break up, so that the powder of broken flakes sinks together and becomes firmer. Its specific gravity will now have risen to $0 \cdot 2$ or $0 \cdot 3$. At this stage it is called 'powder snow', and is in its most attractive condition for ski-runners, who, as they skim down the mountain-side, can turn in it hither and thither at will.

Then, under the influence of alternate heating and cooling, a crust begins to form on the snow surface which tends first to trip the unskilled skier, and then, as it grows in depth, becomes hard, so that a man climbing the mountain must cut steps in it. In this condition it is known as 'firn snow', from which the whole process derives its name. But when the hot spring sun has thawed the top few inches of hard firn snow at midday, ski are again able to get a grip, and it then forms one of the grandest and fastest ski-ing surfaces imaginable. 'Spring snow' is the name given by skirunners to this sun-loosened surface of firn snow. At high alpine altitudes the firn snow becomes so hard that, except on south faces and at midsummer, it is almost permanently icy. It is, however, not true ice, which is far rarer than is commonly believed; that stage comes later, the once whitish firn snow becoming blue and glassy.

Photomicrographs provide a key to the changes described above. Commencing with a snowflake: warmth first causes a blunting of the delicate rays by sublimation, some of the water vapour being trapped and resolidified in the centre of the flake, to make a continuous flat plate of ice. The original rays are still visible (Fig. 4). These plates shimmer like diamonds immediately after a snowfall. Seen by moonlight, when the darkness allows the rainbow colours to shine out undimmed, they are a sight never to be forgotten.

At the same time, some of the flakes begin to fracture, and we also see some reconsolidation of the sublimed water vapour in the form of granules. At this stage the snow has settled into the 'powder snow' beloved of ski-runners.

Next we have a light firn stage. The granules are united into aggregates, due to the alternate heating and cooling. This corresponds to the light sun-crust stages. In the earlier stages of firnification, sublimation is probably the chief factor. In the later stages thawing and freezing due to temperature alternations become more common. Regelation probably plays some part, too, throughout the process.

The grains have now grown in size and a cement binding them together is clearly seen. It is this cement which melts first under the influence of heat, turning the hard firn snow into the loose wet grains of 'spring snow'. The thawing of this cement also causes glacier grains to disintegrate when the sun shines strongly on the glacier surface.

There is an interesting similarity here between ice and metals close to their melting points. In the latter the crystal boundaries are also found to be surfaces of weakness. It is believed, but I think not proved, that when ice freezes it rejects any salts from the interior of the crystals and they find their way to the crystal boundaries and into this cement. Certain it is that, as would be expected from an impure ice, this cement has a lower freezing point than the pure ice crystals, and melts first, releasing them to form 'spring snow' or loose collections of glacier grains as the case may be. 
It is possible that there is a true analogy between the behaviour of ice and metals in this respect.

Fig. $\mathbf{5}$ is a photomicrograph of very advanced firn snow and shows the cement. The difference between advanced firn snow and ice is that in the former some air always remains between the crystals. (So long as there is air between the crystals it is, by definition, snow.)

It is surprising that the actual transition of firn snow into glacier ice has never been observed in detail, or recorded more closely than these photo. graphs show in rather incomplete manner. This is to form the subject of a research now in course of preparation.

If we could descend vertically through the firn region of the glacier, as if by a shaft, we should there too find the snow becoming denser and more ice-like ; and that is how it is hoped to carry out the research on the transition of snow into ice mentioned above.*

\section{Avalanches}

The modern study of snow really derives from a need to understand and prevent (or avoid) avalanche accidents. The study of firnification has thrown a powerful light on the most common winter avalanche-that which comes down soon after a fall of fresh snow.

Fig. 6 shows firnification photomicrographs in diagrammatic form: In $A$ the very new snow is interlocked by its rays, and is therefore safe on all but very steep hills. In $B$ these rays become reduced in size, and the snow particles are therefore mobile. In $C$ the flakes break up and form granules, but still lie loose and mobile. In $D$ the snow is granular and more compact, and is again safe. $B, C$ and $D$ conditions will occur more quickly if the air is warm. In other words, low temperatures prolong the avalanche danger.

We may summarize the whole lore of this type of avalanche in the following very simple words :

(1) Immediately after a fall slopes are safe, or at least safer than they will become later when the sun shines. ( $A$ stage.) This has a practical application. If a party of mountaineers is weatherbound in a hut, it should endeavour to make its escape, other things being equal, as soon as a slightest amelioration in the weather has set in, and not wait until the sun has reappeared.

(2) As soon as the air warms up after a snowfall, the snow becomes mobile, first of course on south, and afterwards on north slopes. ( $B$ and $C$

* For this research it is intended to adapt the boring tools of the prospector, and, by the construction of a specially made saw-edged drill head, to bring up undamaged cores of flrn snow and ice from different levels in the glacier. Such a tool, constructed for me by Messrs. C. Isler and Co., has already yielded promising preliminary results in glacier ice. stages.) The practical import of this is that, again other things being equal, escape should be made by north slopes, which are not reached by avalanche danger until later.

(3) Cold conditions prolong the danger.

(4) As soon as the snow has become denser powder or 'settled' it is safe. ( $D$ stage.)

\section{WIND-PACKING}

The effect of wind upon snow is to pack it hard, forming a crust. From such a crust the erosive action of wind-driven grains cuts out fantastic figures, which may form a serious obstacle to the explorer in polar regions, for they may rise in
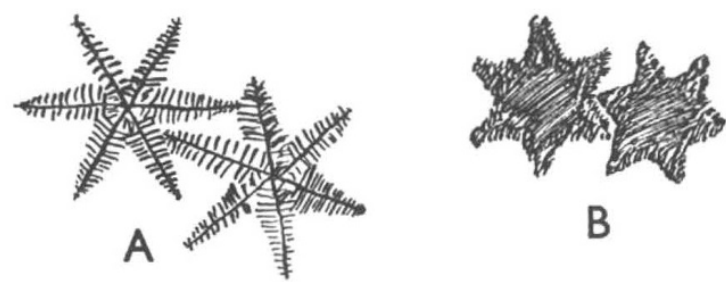

B
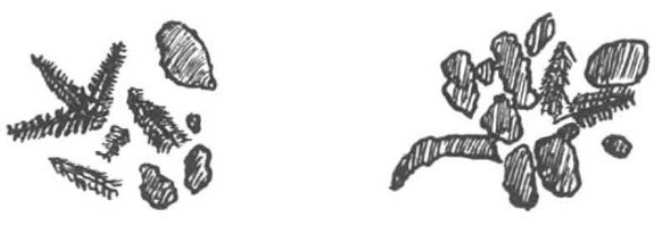

C

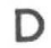

Fig. 6.

Diagram SHOWING THE SAFE AND DANGEROUS STATES OF NEW AND 'SETTLED' SNOW.

high, so-called sastrugi, covering wide areas. These sastrugi have their steep face to the wind, which has a practical application, especially on a flat plain where the wind may be expected to be constant over wide areas -in a fog they provide the traveller with a constant indication of direction.

Cornices, too, are the result of wind action.

The drifting of snow is a study in itself, and a profound one at that. The deposition of snow in drifts is due to a slackening of the wind speed and consequent deposition of the snow grains it was transporting. If the wind still continues to blow while snowdrifts are forming, that is to say, if the snowdrift is not growing in a complete calm, the hardening, or 'wind-packing' as it is called, will extend right through the drift. If this drifting and packing occur on a steep hillside we get a curious happening. The packed snow, when disturbed by the weight of a man, breaks into blocks which slide down the mountain side, causing what 
is called a wind-slab avalanche, which may be very destructive.

It is characteristic of wind slabs that they do not bind themselves to the hillside, but have a hollow space underneath, which renders them all the more unstable.

Photomicrographs of the snow composing one of these wind-packed drifts or slabs showed considerable uniformity in grain size. This indicated a method of approach towards the proof of what had hitherto only been suspected, namely, that the snow had been drifted, since drifting sorts out the grains into uniform sized groups.

A study was made of a whole series of photomicrographs both of natural wind slabs and of wind slabs made under controlled conditions in an out-of-door laboratory. Ultimately it became possible to make this hitherto unexplained phenomenon, which had sent so many brave and wondering mountaineers to their deaths, yield up several of its secrets. Among other things it became possible to tell the mountaineer where on the hillside he can expect the worst wind-slab avalanches, and under what atmospheric conditions they are to be expected.

To put these findings in a nutshell : they are found on slopes to the leeward of the last snowbearing wind, when the general condition of the air is damp.

This conclusion has already borne fruit. Ever since the fatal avalanche on Mount Everest in 1922, when seven porters met their deaths, leaders of the expeditions have been puzzled by unaccountable avalanches bursting from the North Col with apparently no prime cause. They have now come to realize that these fall under just those conditions which I have pointed out, namely, a wet wind depositing the snow in drifts on lee slopes, and they have been able to link them up with the advent of the monsoon. As soon as the damp monsoon wind blows over the North Col the glacier on its lee side becomes a death-trap. An alternative route has now been reconnoitred and will, no doubt, be used in future, as soon as the conditions begin to favour wind slab development.

\section{Origin of the Papuan Insect Fauna}

\section{By L. Evelyn Cheesman}

$\mathrm{T}^{\mathrm{H}}$ HE island of New Guinea is a centre of distribution for species belonging to the Papuan fauna, which is very distinct and very rich in variety of forms. Yet the bulk of this huge island is part of the Himalayan geanticline, and therefore geologically recent. Since the fauna cannot have evolved upon land recently raised from the sea, there must have been older land from which the new land was populated.

Palæogeologists such as Ortmann, Lapparent, Arldt and others have postulated a land-mass which during the Middle Cretaceous extended from the Asiatic continent south to New Caledonia and eastward to Sumatra and Java. Some time during the Upper Cretaceous, according to the same authorities, New Guinea became separated from Borneo, Celebes and the Philippines, and also from New Caledonia. Later, the entire island is supposed to have been submerged until the Miocene-Pliocene folding movement raised the central ranges and land to the south.

Biological evidence with regard to the distribution of insect species supports these theories of former land-masses up to a certain point. For the Papuan insect fauna appears to be of oriental origin, showing decided affinities with the fauna of the Philippines, New Caledonia and the Moluccas; but is distant from that of Malaysia, with the exception of a few widely dispersed species which may represent a much older fauna.

The Papuan insect fauna has also spread in a south-easterly direction as far as the Society Islands in the mid-Pacific. I think that later we shall find the Papuan element in the Pacific even stronger than it appears, when we are more familiar with true Papuan forms and are in a position to check old records. For I have discovered in many cases that species recorded as IndoMalayan, Austro-Malayan and Australasian are in reality Papuan; even so-called Australian species are very often those recorded from tropical Queensland and therefore are also Papuan.

The origin of the peculiar endemic fauna and flora of New Guinea, however, is not explained by the work of geologists. Old mountains of continental rock do exist in New Guinea, in the central ranges and to the north ; but these have not been investigated, and may have been submerged before the Tertiary. On the north coast, however, where I recently made a collecting expedition on behalf of the British Museum (Natural History), the Cyclops Mountains and 